\title{
Article \\ Modulation of Diverse Procoagulant Venom Activities by Combinations of Platinoid Compounds
}

\author{
Vance G. Nielsen (D)
}

Citation: Nielsen, V.G. Modulation of Diverse Procoagulant Venom Activities by Combinations of Platinoid Compounds. Int. J. Mol. Sci. 2021, 22, 4612. https://doi.org/ $10.3390 /$ ijms 22094612

Academic Editor: Yuri N. Utkin

Received: 13 March 2021

Accepted: 26 April 2021

Published: 28 April 2021

Publisher's Note: MDPI stays neutral with regard to jurisdictional claims in published maps and institutional affiliations.

Copyright: (c) 2021 by the author Licensee MDPI, Basel, Switzerland. This article is an open access article distributed under the terms and conditions of the Creative Commons Attribution (CC BY) license (https:// creativecommons.org/licenses/by/ $4.0 /$ )
Department of Anesthesiology, College of Medicine, University of Arizona, Tucson, AZ 85719, USA; vgnielsen333@gmail.com

\begin{abstract}
Procoagulant snake venoms have been inhibited by the ruthenium containing compounds CORM-2 and $\mathrm{RuCl}_{3}$ separately, presumably by interacting with critical histidine or other sulfurcontaining amino acids on key venom enzymes. However, combinations of these and other platinoid containing compounds could potentially increase, decrease or not affect the procoagulant enzyme function of venom. Thus, the purpose of this investigation was to determine if formulations of platinoid compounds could inhibit venom procoagulant activity and if the formulated compounds interacted to enhance inhibition. Using a human plasma coagulation kinetic model to assess venom activity, six diverse venoms were exposed to various combinations and concentrations of CORM-2, CORM-3, $\mathrm{RuCl}_{3}$ and carboplatin (a platinum containing compound), with changes in venom activity determined with thrombelastography. The combinations of CORM-2 or CORM-3 with $\mathrm{RuCl}_{3}$ were found to enhance inhibition significantly, but not in all venoms nor to the same extent. In sharp contrast, carboplatin-antagonized CORM-2 mediated the inhibition of venom activity. These preliminary results support the concept that platinoid compounds may inhibit venom enzymatic activity at the same or different molecular sites and may antagonize inhibition at the same or different sites. Further investigation is warranted to determine if platinoid formulations may serve as potential antivenoms.
\end{abstract}

Keywords: procoagulant venom; ruthenium; platinum; thrombelastography; carbon monoxide releasing molecule

\section{Introduction}

For the past few years this laboratory has focused on quantifying the effects of scores of snake venoms [1-4] and anticoagulant enzymes isolated from such venoms [5,6] on human plasmatic coagulation, with an emphasis on the inhibitory action of carbon monoxide (CO) on such anticoagulant activity. The source of site-directed $\mathrm{CO}$ application to these venoms in isolation prior to placement into human plasma was release from a ruthenium ( $\mathrm{Ru}$ )-based carbon monoxide releasing molecule (tricarbonyldichlororuthenium(II) dimer (CORM-2)). The specificity of CO-mediated effects was by the concurrent exposure of venom to an inactive releasing molecule that had undergone a degradation [1-4,6] with the result that this molecule would not inhibit venom activity to the extent that CORM-2 had inhibited activity [1-4,6]. This paradigm is decades old, but it was challenged in the setting of $\mathrm{K}^{+}$ channel inhibition [7] and assessment of antibacterial activity [8] exerted by Ru(II) based carbon monoxide releasing molecules (CORM). These recent investigations determined that these $\mathrm{Ru}(\mathrm{II}) \mathrm{CORM}$ formed a transition state that, after releasing $\mathrm{CO}$, would bind to histidine [7,8], methionine [8], glutathione [8], or cysteine [8]. In response to these new findings $[7,8]$, it was subsequently reported that purified phospholipase $\mathrm{A}_{2}$ isolated from bee venom was inhibited by CORM-2 via a CO-independent mechanism, with inhibition of the venom by CORM-3 (tricarbonylchloro(glycinato)ruthenium) likely also dependent on a $\mathrm{Ru}(\mathrm{II})$-based mechanism [9]. Thereafter, anticoagulant metalloproteinase activity in venoms collected from mambas was found to be inhibited by CORM-2 by a similar CO-independent mechanism [10], and, finally, the procoagulant activity exerted by metalloproteinases 
and serine proteases was found to be inhibited by CORM-2 and ruthenium(III) chloride $\left(\mathrm{RuCl}_{3}\right)$ [11]. Thus, as suggested by the works of the past several months [9-11], it is the ruthenium species, not $\mathrm{CO}$, that are binding to key anticoagulant/procoagulant venom enzymes in a heme-independent and perhaps irreversible fashion.

It is of interest that multiple Ru-based molecular species have been synthesized and investigated as potential chemotherapeutic agents to replace the toxic platinum-based medications (e.g., cisplatin, carboplatin) used to treat various cancers [12-19]. Thus, investigations have demonstrated that $\mathrm{Ru}(\mathrm{II})$-based compounds covalently bind to histidine, methionine, glutathione, or cysteine $[8,12-14]$, and $\mathrm{Ru}(\mathrm{III})$-based compounds similarly bind histidine and cysteine [15-19]. The platinum (Pt)-based compounds cisplatin and carboplatin also bind histidine and methionine [20]. These binding characteristics of $\mathrm{Ru}$ compounds to specific amino acid residues may explain why CORM-2 and $\mathrm{RuCl}_{3}$ separately have inhibited snake venom and isolated enzyme activities [1-6,9-11], as highly conserved histidines and disulfide bridges that are critical to function are found in snake venom metalloproteinases (MP) [21,22], snake venom serine proteases (SP) [23,24] and phospholipase $\mathrm{A}_{2}\left(\mathrm{PLA}_{2}\right)[25,26]$. Taken as a whole, small molecular weight Ru-based or Pt-based compounds may inhibit anticoagulant/procoagulant snake venom activity by binding to a hereto unappreciated Achilles' heel of highly conserved amino acid residues essential to functions shared across multiple enzyme types.

However, the inhibitory effects of any class of compound are not just based on valance, but also on size, composition, and other characteristics that can change the affinity of a compound for a ligand. The structures of CORM-2, CORM-3, $\mathrm{RuCl}_{3}$ and carboplatin are displayed in Figure 1. It is of note that CORM-2 and $\mathrm{RuCl}_{3}$ have been found to have similar or no inhibitory effects on various procoagulant venoms when tested separately [11]. This finding opened the possibility that the Ru-based and Pt-based compounds may bind to the same critical amino acid residue, with perhaps different affinity to different residues that are enzymatically important, or perhaps to more than two molecular sites on any given enzyme. It should also be noted that the proteome of such venoms contains a great deal of similar or diverse enzymes with different effects on coagulation that summate into primarily anticoagulant or procoagulant activities [1-4]. To reiterate, these enzymes include SP, MP, kallikrein-like SP, and molecules that closely resemble human coagulation factors $\mathrm{V}(\mathrm{FV})$ and X (FX) [27-35], which are found in the indicated venoms displayed in Table 1. These venoms were chosen as they have already demonstrated marked vulnerability to inhibition by CORM- 2 or $\mathrm{RuCl}_{3}$ in previous works $[1-4,11,36]$. Thus, they would serve well to achieve the subsequently presented goals.<smiles></smiles>

CORM-2

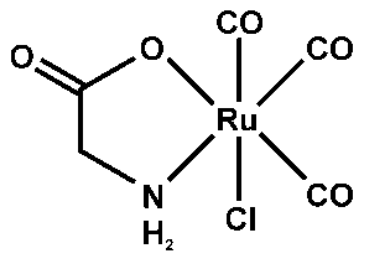

CORM-3<smiles>Cl[R1](Cl)Cl</smiles>

Ruthenium chloride<smiles>CC12CCCC1(C(=O)O[P+](N)(N)N)C(=O)O2</smiles>

Carboplatin

Figure 1. The structures and names of the Ru-based and platinum $(\mathrm{Pt})$-based compounds used in the present study. 
Table 1. Properties of procoagulant snake venoms investigated.

\begin{tabular}{lcc}
\hline \multicolumn{1}{c}{ Species } & Common Name & Proteome \\
\hline Bothrops moojeni [27] & Brazilian Lancehead & SP, MP \\
Calloselasma rhodostoma [28] & Malayan Pit Viper & SP, MP \\
Echis leucogaster [29-31] & White-Bellied Carpet Viper & SP, MP \\
Heloderma suspectum [32,33] & Gila Monster & Kallikrein-like SP \\
Oxyuranus microlepidotus [34] & Inland Taipan & Factor V-like, SP, MP \\
Pseudonaja textilis [35] & Eastern Brown Snake & Factor V, X-like SP, MP \\
\hline
\end{tabular}

Given the aforementioned molecular complexity, the goal of this manuscript was to determine the effects of CORM-2, CORM-3, carboplatin and $\mathrm{RuCl}_{3}$ exposure (separately and as a formulation) on a variety of diverse procoagulant snake venoms to provide insight into any interactions of the compounds on venom procoagulant activity as assessed by changes in human plasmatic coagulation monitored with thrombelastography.

\section{Results}

2.1. Assessment of CORM-2 and $\mathrm{RuCl}_{3}$, Separately and in Combination, on the Procoagulant Activity of B. moojeni, C. rhodostoma, E. leucogaster and O. microlepidotus

The subsequent results were obtained using concentrations, or fractions thereof, of the aforementioned venoms previously published using these methods [1-6,36]; specifically, B. moojeni venom had a final concentration of $2 \mu \mathrm{g} / \mathrm{mL}, C$. rhodostoma a venom concentration of $5 \mu \mathrm{g} / \mathrm{mL}$, E. leucogaster a venom concentration of $1 \mu \mathrm{g} / \mathrm{mL}$ and O. microlepidotus a venom concentration of $1 \mu \mathrm{g} / \mathrm{mL}$ in the plasma mixtures tested. Venom concentrations were selected on a performance basis wherein the activation of coagulation by the venom statistically exceeded the activation observed by contact activation with thrombelastographic cup and pin contact with plasma, as previously described [1-6,36]. All venom solutions were added as a $1 \%$ addition to the plasma mix in our thrombelastographic system [1-6,36]. This dilution is critical, as it reduces the concentration of CORM-2 to $1 \mu \mathrm{M}$, a concentration at which this compound does not affect coagulation kinetics [4]. Further, it has been demonstrated that concentrations of $\mathrm{RuCl}_{3}$ at or below $1 \mu \mathrm{M}$ do not significantly affect human plasmatic coagulation, meaning that exposure of venom to up to $100 \mu \mathrm{M}$ in isolation in this system should not affect the interpretation of changes in venom procoagulant activity [37]. With regard to the concentrations of CORM-2 and $\mathrm{RuCl}_{3}$ used in the isolated exposures, they were as follows: B. moojeni venom was exposed to $0-1 \mathrm{mM}$ CORM-2 and $0-100 \mu \mathrm{M} \mathrm{RuCl}{ }_{3} ;$ C. rhodostoma venom was exposed to $0-50 \mu \mathrm{M}$ CORM-2 and 0-50 $\mathrm{RuCl}_{3}$; E. leucogaster venom was exposed to 0-100 $\mu \mathrm{M}$ CORM-2 and $0-100 \mu \mathrm{M} \mathrm{RuCl}$; and, O. microlepidotus venom to $0-100 \mu \mathrm{M}$ CORM-2 and $0-100 \mu \mathrm{M} \mathrm{RuCl}_{3}$. Lastly, the thrombelastographic model utilized describes coagulation kinetics with the following three variables: time to maximum thrombus generation (TMRTG, minutes-a measure of time to onset of coagulation), maximum rate of thrombus generation (MRTG, dynes $/ \mathrm{cm}^{2} / \mathrm{sec}$ - a measure of the velocity of clot growth) and total thrombus generation (TTG, dynes $/ \mathrm{cm}^{2}$-a measure of clot strength). The results of exposing the four venoms to CORM-2 and $\mathrm{RuCl}_{3}$ separately or in combination are displayed in the following Figures 2 and 3.

As seen in Figure 2's left panels, exposure of B. moojeni venom to $1 \mathrm{mM}$ CORM-2 (depicted as $\mathrm{Ru}(\mathrm{II})$ ) resulted in a significant increase in TMRTG and decrease in MRTG values compared to CORM-2 naïve venom, indicative of inhibition of procoagulant activity. In contrast, exposure of $B$. moojeni venom to $100 \mu \mathrm{M} \mathrm{RuCl}{ }_{3}$ (depicted as $\mathrm{Ru}(\mathrm{III})$ ) did not significantly diminish procoagulant activity in this dataset. When $B$. moojeni venom was exposed to the combination of CORM-2 and $\mathrm{RuCl}_{3}$, TMRTG values were far more increased and MRTG values decreased compared to all other conditions, with the inhibition of the procoagulant activity due to significant interaction of the two Ru-based compounds. Lastly, there were no effects of the Ru-based compounds on the final clot strength generated by the procoagulant activity of $B$. moojeni venom except in the condition wherein both were 
present, resulting in TTG values significantly greater than the condition wherein venom alone was present.
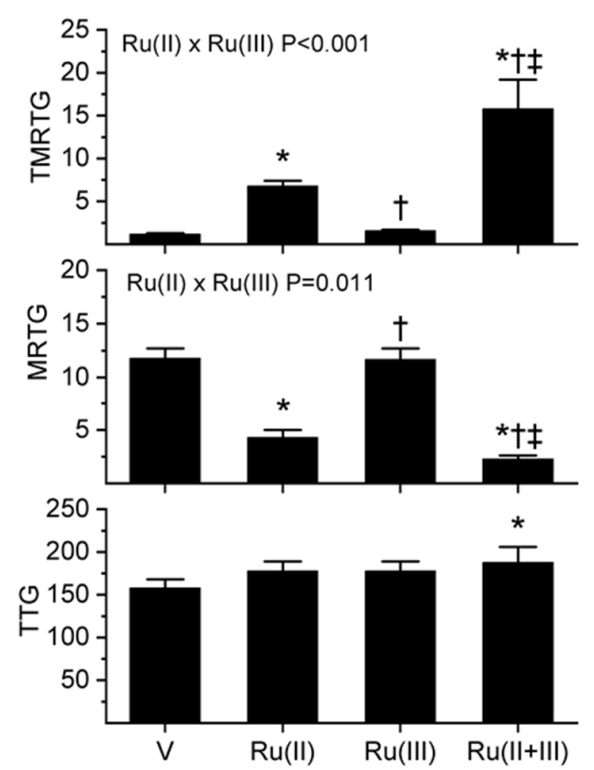
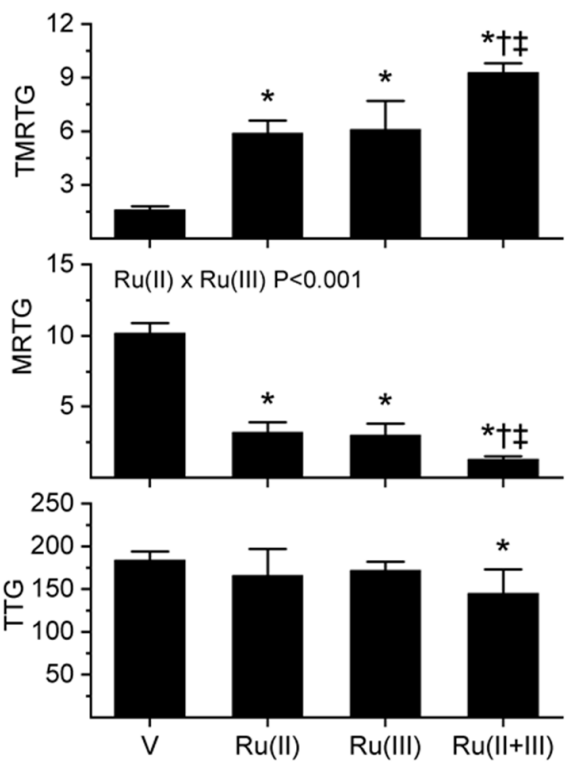

Figure 2. Procoagulant activity of B. moojeni venom (left panels) and C. rhodostoma venom (right panels) in plasma after exposure to CORM-2 (Ru(II)), $\mathrm{RuCl}_{3}(\mathrm{Ru}(\mathrm{III}))$ or both $(\mathrm{Ru}(\mathrm{II}+\mathrm{III}))$ in isolation. Data is presented as mean $\pm \mathrm{SD}$. $\mathrm{V}=$ venom; $\mathrm{Ru}(\mathrm{II})=\mathrm{V}+\mathrm{CORM}-2$ in PBS; $\mathrm{Ru}(\mathrm{III})=\mathrm{V}+\mathrm{RuCl}_{3}$; $\mathrm{Ru}(\mathrm{II}+\mathrm{III})=\mathrm{V}+\mathrm{CORM}-2$ and $\mathrm{RuCl}_{3} .{ }^{*} p<0.05$ vs. V; $+p<0.05$ vs. $\mathrm{Ru}(\mathrm{II}) ; \ddagger p<0.05$ vs. $\mathrm{Ru}(\mathrm{III})$ via one-way analysis of variance (ANOVA) with Holm-Sidak post hoc test. Significant interactions between CORM-2 and $\mathrm{RuCl}_{3}(\mathrm{Ru}(\mathrm{II}) \times \mathrm{Ru}(\mathrm{III}))$ determined with two-way ANOVA are displayed within individual parameter graphics.
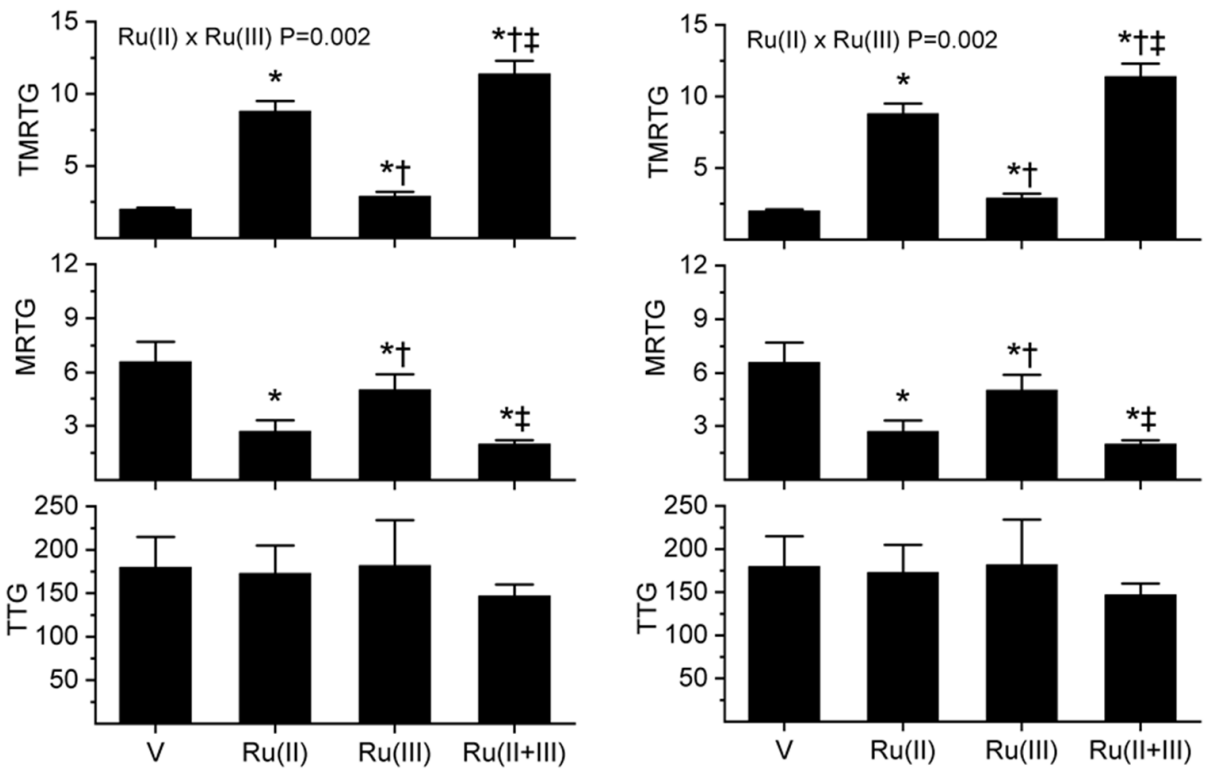

Figure 3. Procoagulant activity of E. leucogaster venom (left panels) and O. microlepidotus venom (right panels) in plasma after exposure to CORM-2 ( $\mathrm{Ru}(\mathrm{II})), \mathrm{RuCl}_{3}(\mathrm{Ru}(\mathrm{III}))$ or both $(\mathrm{Ru}(\mathrm{II}+\mathrm{III}))$ in isolation. Data is presented as mean $\pm \mathrm{SD}$. V = venom; $\mathrm{Ru}(\mathrm{II})=\mathrm{V}+\mathrm{CORM}-2$ in PBS; $\mathrm{Ru}(\mathrm{III})=\mathrm{V}+\mathrm{RuCl}_{3}$; $\mathrm{Ru}(\mathrm{II}+\mathrm{III})=\mathrm{V}+\mathrm{CORM}-2$ and $\mathrm{RuCl}_{3} .{ }^{*} p<0.05$ vs. V; $+p<0.05$ vs. $\mathrm{Ru}(\mathrm{II}) ; \ddagger p<0.05 \mathrm{vs.} \mathrm{Ru}(\mathrm{III})$. Significant interactions between CORM-2 and $\mathrm{RuCl}_{3}(\mathrm{Ru}(\mathrm{II}) \times \mathrm{Ru}(\mathrm{III}))$ determined with two-way ANOVA are displayed within individual parameter graphics. 
With regard to the results obtained with $C$. rhodostoma venom, these are displayed in the right panels of Figure 2. Exposure of C. rhodostoma venom to $50 \mu \mathrm{M}$ CORM-2 resulted in a significant increase in TMRTG and decrease in MRTG values compared to CORM-2 naïve venom, revealing procoagulant activity inhibition. Similarly, exposure of $C$. rhodostoma venom to $50 \mu \mathrm{M} \mathrm{RuCl} 3$ significantly diminished procoagulant activity, evidenced by an increase in TMRTG values and a decrease in MRTG values compared to venom not exposed to $\mathrm{RuCl}_{3}$. When $\mathrm{C}$. rhodostoma venom was exposed to the combination of CORM-2 and $\mathrm{RuCl}_{3}$, TMRTG values were far more increased and MRTG values decreased compared to all other conditions, with the inhibition of the procoagulant activity assessed by changes in MRTG due to a significant interaction of the two Ru-based compounds. Lastly, there was a significant decrease in TTG values when the venom was exposed to both CORM-2 and $\mathrm{RuCl}_{3}$ compared to venom exposed to neither compound. In summary, these diverse venoms displayed an enhanced inhibition of procoagulant activity following exposure to the combination of CORM-2 and $\mathrm{RuCl}_{3}$ compared to separate exposures of either compound.

As for the next two venoms tested, the results obtained with E. leucogaster venom and O. microlepidotus venom are displayed in the left and right panels of Figure 3, respectively. With regard to E. leucogaster venom, exposure to $100 \mu \mathrm{M}$ CORM-2 resulted in a significant increase in TMRTG and decrease in MRTG values compared to CORM-2 naïve venom, demonstrating procoagulant activity inhibition. Similarly, exposure of E. leucogaster venom to $100 \mu \mathrm{M} \mathrm{RuCl}_{3}$ significantly diminished procoagulant activity, evidenced by an increase in TMRTG values and a decrease in MRTG values compared to venom not exposed to $\mathrm{RuCl}_{3}$. However, the inhibition of procoagulant activity was significantly less than that observed with CORM-2. When E. leucogaster venom was exposed to the combination of CORM-2 and $\mathrm{RuCl}_{3}$, TMRTG values were significantly more increased compared to all other conditions. Inhibition of venom activity assessed by changes in TMRTG due to a significant interaction of the two Ru-based compounds was also present. Further, MRTG values were significantly decreased compared to venom without exposures and venom exposed to $\mathrm{RuCl}_{3}$ but not different from venom exposed only to CORM-2. Lastly, there were no significant changes in TTG values between the conditions.

The results obtained with $O$. microlepidotus venom are displayed in the right panels of Figure 3. Exposure of this venom to $100 \mu \mathrm{M}$ CORM-2 resulted in a significant increase in TMRTG, decrease in MRTG, and decrease in TTG values compared to CORM-2 naïve venom, demonstrating procoagulant activity inhibition. In sharp contrast, exposure of O. microlepidotus venom to $100 \mu \mathrm{M} \mathrm{RuCl}_{3}$ did not significantly affect procoagulant activity. Lastly, when O. microlepidotus venom was exposed to the combination of CORM-2 and $\mathrm{RuCl}_{3}$, the decrease in procoagulant activity was not significantly different from venom exposed to CORM-2 alone but significantly more inhibited than venom without exposure to any compounds or exposed to $\mathrm{RuCl}_{3}$.

In conclusion, these series of experiments with these four diverse venoms demonstrated very different patterns of inhibition by $\mathrm{CORM}-2, \mathrm{RuCl}_{3}$, or the combination of these two compounds.

\subsection{Assessment of CORM-3 and $\mathrm{RuCl}_{3}$, Separately and in Combination, on the Procoagulant Activity of B. moojeni, C. rhodostoma, P. textilis and H. suspectum}

For this third series of experiments, B. moojeni venom had a final plasma sample concentration of $2 \mu \mathrm{g} / \mathrm{mL}, C$. rhodostoma a venom concentration of $5 \mu \mathrm{g} / \mathrm{mL}, P$. textilis a venom concentration of $0.1 \mu \mathrm{g} / \mathrm{mL}$, and $H$. suspectum venom a concentration of $10 \mu \mathrm{g} / \mathrm{mL}$. All other aspects of the plasma mix used were similar to that of the previous series. The concentrations of CORM-2 and $\mathrm{RuCl}_{3}$ used in the isolated exposures were as follows: B. moojeni venom was exposed to $1 \mathrm{mM} \mathrm{CORM}-3$ and $100 \mu \mathrm{M} \mathrm{RuCl}_{3}$; C. rhodostoma venom was exposed to $50 \mu \mathrm{M}$ CORM-3 and $50 \mathrm{RuCl}_{3} ;$ P. textilis venom was exposed to $100 \mu \mathrm{M}$ CORM-2 and $100 \mu \mathrm{M} \mathrm{RuCl} 3$; and, H. suspectum venom to $1 \mathrm{mM}$ CORM-2 and $100 \mu \mathrm{M}$ $\mathrm{RuCl}_{3}$. The results of exposing the four venoms to CORM-3 and $\mathrm{RuCl}_{3}$ separately or in combination are displayed in the following Figures 4 and 5. 

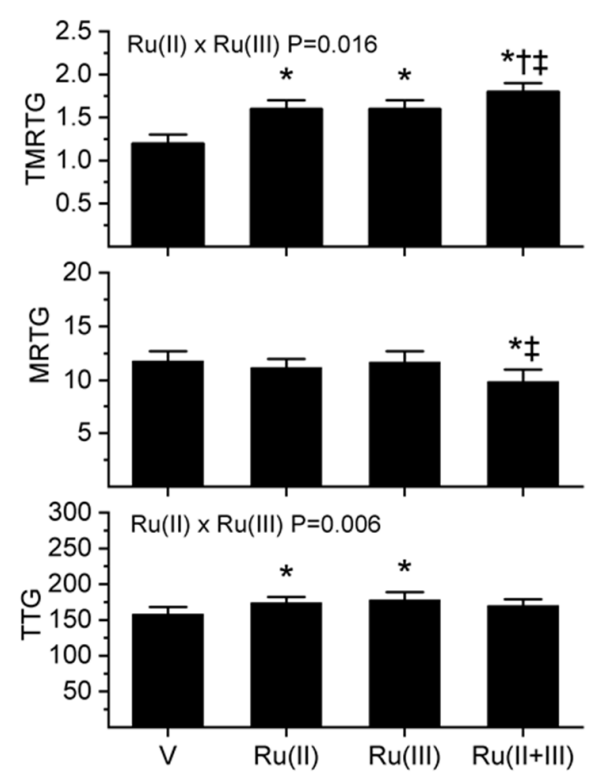
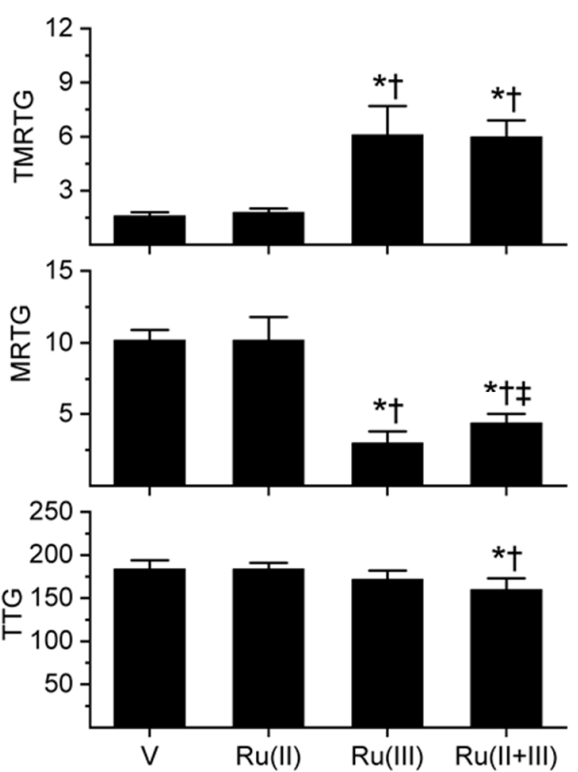

Figure 4. Procoagulant activity of B. moojeni venom (left panels) and C. rhodostoma venom (right panels) in plasma after exposure to CORM-3 $(\mathrm{Ru}(\mathrm{II})), \mathrm{RuCl}_{3}(\mathrm{Ru}(\mathrm{III}))$ or both $(\mathrm{Ru}(\mathrm{II}+\mathrm{III}))$ in isolation. Data is presented as mean $\pm \mathrm{SD}$. $\mathrm{V}=$ venom; $\mathrm{Ru}(\mathrm{II})=\mathrm{V}+\mathrm{CORM}-3$ in PBS; $\mathrm{Ru}(\mathrm{III})=\mathrm{V}+\mathrm{RuCl}_{3}$; $\mathrm{Ru}(\mathrm{II}+\mathrm{III})=\mathrm{V}+\mathrm{CORM}-3$ and $\mathrm{RuCl}_{3} .{ }^{*} p<0.05$ vs. V; $+p<0.05$ vs. $\mathrm{Ru}(\mathrm{II}) ; \ddagger p<0.05$ vs. $\mathrm{Ru}(\mathrm{III})$. Significant interactions between CORM-3 and $\mathrm{RuCl}_{3}(\mathrm{Ru}(\mathrm{II}) \times \mathrm{Ru}(\mathrm{III}))$ determined with two-way ANOVA are displayed within individual parameter graphics.
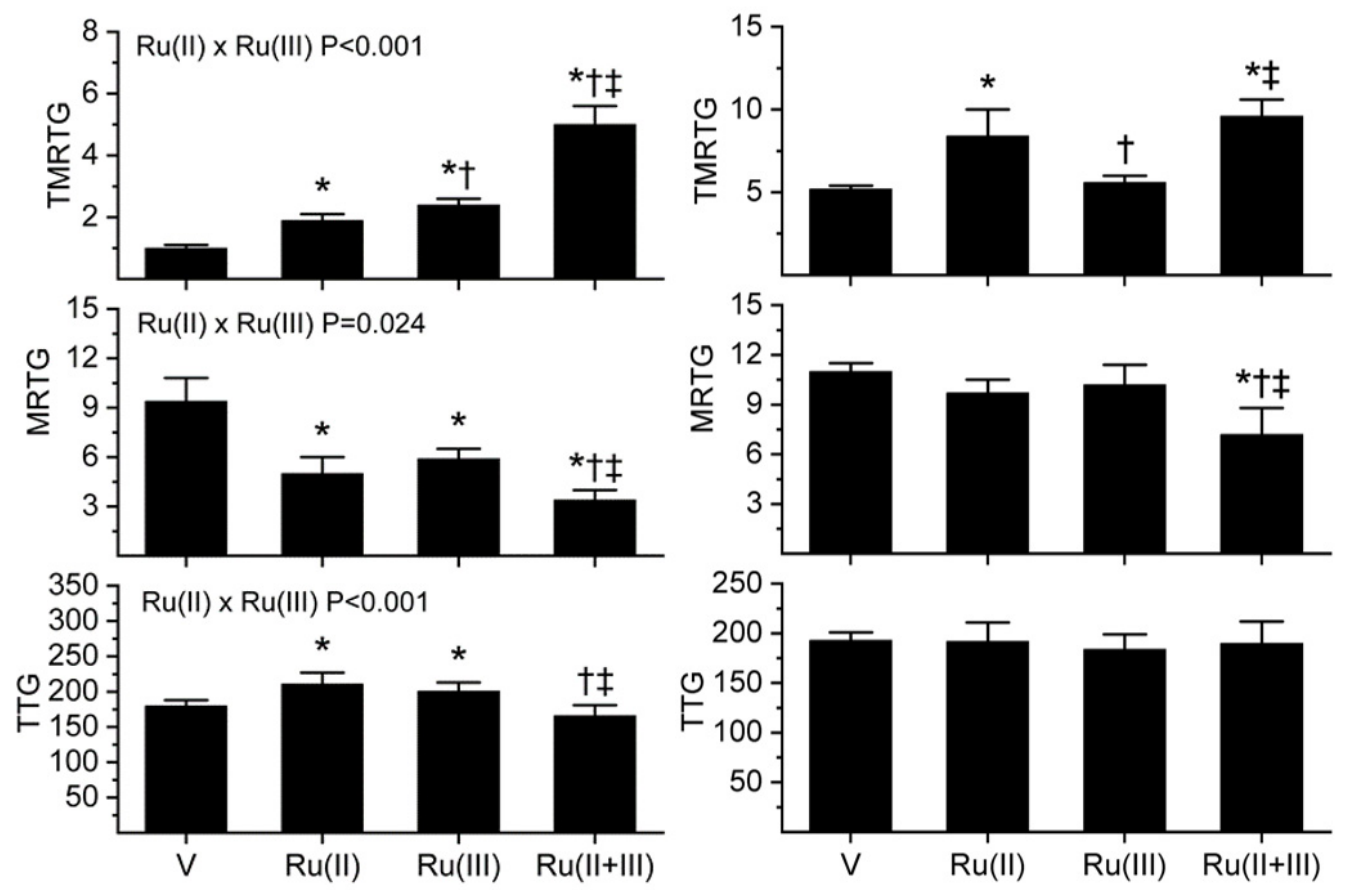

Figure 5. Procoagulant activity of $P$. textilis venom (left panels) and $H$. suspectum venom (right panels) in plasma after exposure to CORM-3 $(\mathrm{Ru}(\mathrm{II})), \mathrm{RuCl}_{3}(\mathrm{Ru}(\mathrm{III}))$ or both $(\mathrm{Ru}(\mathrm{II}+\mathrm{III}))$ in isolation. Data is presented as mean $\pm \mathrm{SD}$. $\mathrm{V}=$ venom; $\mathrm{Ru}(\mathrm{II})=\mathrm{V}+\mathrm{CORM}-3$ in PBS; $\mathrm{Ru}(\mathrm{III})=\mathrm{V}+\mathrm{RuCl}_{3}$; $\mathrm{Ru}(\mathrm{II}+\mathrm{III})=\mathrm{V}+\mathrm{CORM}-3$ and $\mathrm{RuCl}_{3} .{ }^{*} p<0.05$ vs. V; $+p<0.05$ vs. $\mathrm{Ru}(\mathrm{II}) ; \ddagger p<0.05 \mathrm{vs} . \mathrm{Ru}(\mathrm{III})$. Significant interactions between CORM-3 and $\mathrm{RuCl}_{3}(\mathrm{Ru}(\mathrm{II}) \times \mathrm{Ru}(\mathrm{III}))$ determined with two-way ANOVA are displayed within individual parameter graphics. 
As seen in Figure 4 in the left panels, exposure of B. moojeni venom to 1 mM CORM-3 or $100 \mu \mathrm{M} \mathrm{RuCl}_{3}$ resulted in a significant increase in TMRTG compared to additive naïve venom, indicative of inhibition of procoagulant activity. In contrast, exposure of $B$. moojeni venom to CORM-3 or $\mathrm{RuCl}_{3}$ did not significantly change MRTG values. Exposure to both Ru-based compounds significantly increased TMRTG values compared to all other conditions, and MRTG values were decreased compared to venom without exposure to additives or exposure to $\mathrm{RuCl}_{3}$. TTG values were significantly increased by either Rubased compound but TTG values decreased to values observed with venom not exposed to additives. This change in TTG values resulted in a significant interaction between CORM-3 and $\mathrm{RuCl}_{3}$.

The results obtained with $C$. rhodostoma venom are displayed in the right panels of Figure 4. Exposure of this venom to $100 \mu \mathrm{M}$ CORM-3 resulted in no significant effect on procoagulant activity. In sharp contrast, exposure of $C$. rhodostoma venom to $100 \mu \mathrm{M}$ $\mathrm{RuCl}_{3}$ resulted in a significant increase in TMRTG and decrease in MRTG compared to $\mathrm{RuCl}_{3}$ naïve venom or CORM-3 exposed venom but not different from $\mathrm{RuCl}_{3}$ exposed venom. With regard to MRTG values, the combination of CORM-3 and $\mathrm{RuCl}_{3}$ resulted in values significantly smaller than $\mathrm{RuCl}_{3}$ naïve venom or CORM-3 exposed venom; however, MRTG values under these conditions were significantly greater than that associated with venom exposed to $\mathrm{RuCl}_{3}$ alone. Lastly, when C. rhodostoma venom was exposed to the combination of CORM-3 and $\mathrm{RuCl}_{3}$, TTG values were significantly smaller than those observed in the $\mathrm{RuCl}_{3}$ naïve venom or CORM-3 exposed venom sample.

Data obtained from experiments performed with P. textilis venom and H. suspectum venom are depicted in the left and right panels of Figure 5, respectively. P. textilis venom exposed to $100 \mu \mathrm{M}$ CORM-3 or $100 \mu \mathrm{M} \mathrm{RuCl} 3$ resulted in a significant increase in TMRTG, decrease in MRTG, and increase in TTG values compared to additive naïve venom. Further, when exposed to both CORM-3 and $\mathrm{RuCl}_{3}$, TMRTG values significantly larger than and MRTG values significantly smaller than the other three conditions were observed. In contrast, TTG values observed after venom was exposed to both CORM-3 and $\mathrm{RuCl}_{3}$ were significantly smaller than in samples with venom exposed to either Ru-based compound separately. Lastly, CORM-3 and $\mathrm{RuCl}_{3}$ demonstrated significant interactions on venom activity, as seen in the two-way ANOVA analyses.

Data obtained from experiments performed with H. suspectum venom are presented in the right panel of Figure 5. Exposure of this venom to CORM-3 resulted in a significant increase in TMRTG values in plasma but no change in either MRTG or TTG values. Exposure of $\mathrm{H}$. suspectum venom to $\mathrm{RuCl}_{3}$ resulted in no significant changes in any of the coagulation kinetic parameters. However, exposure to both CORM-3 and $\mathrm{RuCl}_{3}$ resulted in TMRTG values significantly greater than venom not exposed to additives or venom exposed to $\mathrm{RuCl}_{3}$. In contrast, MRTG values were significantly decreased by the combination of CORM-3 and $\mathrm{RuCl}_{3}$ compared to all other conditions. Not changes in TTG were noted between the conditions. In summary, the exposure of H. suspectum venom to CORM-3 and $\mathrm{RuCl}_{3}$ in various combinations resulted in significant but quantitatively small inhibition of procoagulant activity.

In conclusion, this series of experiments demonstrated a diverse response to CORM-3 mediated inhibition compared to CORM-2 attenuation of activity with four very different venoms.

2.3. Assessment of CORM-2 and Carboplatin, Separately and in Combination, on the Procoagulant Activity of B. moojeni and C. rhodostoma Venoms

As with the previous experiments, B. moojeni venom had a final concentration of $2 \mu \mathrm{g} / \mathrm{mL}$ and C. rhodostoma a venom concentration of $5 \mu \mathrm{g} / \mathrm{mL}$. All other aspects of the plasma mix used are similar to that of the two previous series except that the venoms were exposed to different combinations of carboplatin and CORM-2. The concentrations of carboplatin and CORM-2 used in the isolated exposures were as follows: B. moojeni venom was exposed to $100 \mu \mathrm{M}$ carboplatin (depicted as Pt(II)) and $1 \mathrm{mM}$ CORM-2; and, C. rhodostoma venom was exposed to $100 \mu \mathrm{M}$ carboplatin and $100 \mu \mathrm{M}$ CORM-2. The results 
of exposing these two venoms to carboplatin and CORM-2 separately or in combination are displayed in the following Figure 6, with data generated with B. moojeni venom in the left panels and data obtained with $C$. rhodostoma venom in the right panels.
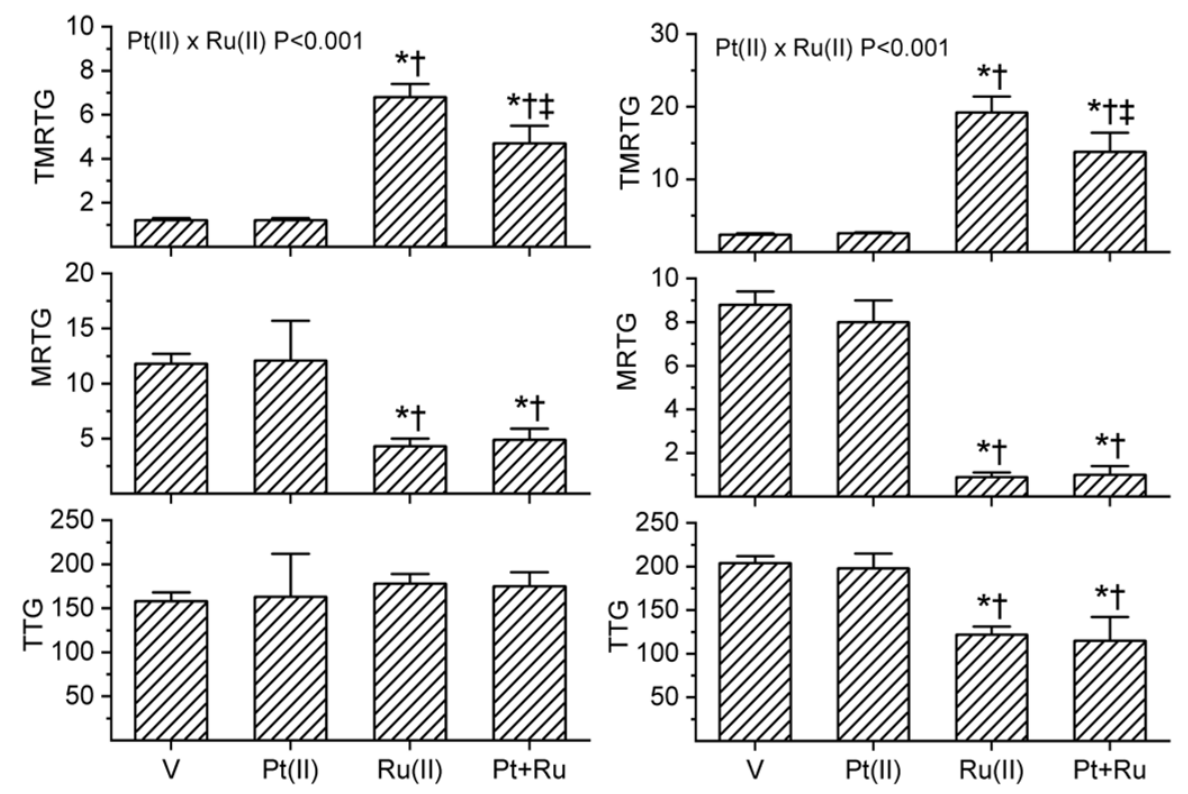

Figure 6. Procoagulant activity of B. moojeni venom (left panels) and C. rhodostoma venom (right panels) in plasma after exposure to carboplatin (Pt(II)), CORM-2 (Ru(II)), or both ( $\mathrm{Pt}+\mathrm{Ru})$ in isolation. Data is presented as mean $\pm \mathrm{SD}$. V = venom; $\mathrm{Pt}(\mathrm{II})=\mathrm{V}+$ carboplatin in PBS; $\mathrm{Ru}(\mathrm{II})=\mathrm{V}+\mathrm{CORM}-2$; $\mathrm{Pt}+\mathrm{Ru}=\mathrm{V}+$ carboplatin and CORM-2. ${ }^{*} p<0.05$ vs. $\mathrm{V} ; \dagger p<0.05$ vs. $\mathrm{Pt}(\mathrm{II}) ; \ddagger p<0.05 \mathrm{vs} . \mathrm{Ru}$ (II) via one-way analysis of variance (ANOVA) with Holm-Sidak post hoc test. Significant interactions between carboplatin and CORM-2 $(\mathrm{Pt}(\mathrm{II}) \times \mathrm{Ru}(\mathrm{II}))$ determined with two-way ANOVA are displayed within individual parameter graphics.

As seen in Figure 6 in the left panels, exposure of B. moojeni venom to carboplatin resulted in no significant change in any of the coagulation kinetic parameters compared to samples with venom without additives. CORM-2 exposure resulted in significantly increased TMRTG and decreased MRTG values compared to CORM-2 naïve or carboplatin exposed venom samples. When carboplatin and CORM-2 were combined, TMRTG values were significantly different from the other three conditions with the important observation that the addition of carboplatin to CORM-2 decreased TMRTG values compared to samples with CORM-2 exposure. The interaction between carboplatin and CORM- 2 was significant for TMRTG values, with carboplatin opposing CORM-2 mediated inhibition of the procoagulant activity of this venom. Lastly, no statistically significant changes in TTG values were noted between the four conditions.

The results obtained with $C$. rhodostoma venom are displayed in the right panels of Figure 6. Exposure of this venom to $100 \mu \mathrm{M}$ carboplatin resulted in no significant effect on procoagulant activity. In sharp contrast, exposure of $C$. rhodostoma venom to $100 \mu \mathrm{M}$ CORM-2 resulted in a significant increase in TMRTG, decrease in MRTG and decrease in TTG values compared to CORM-2 naïve venom or carboplatin. Exposure of this venom to the combination of carboplatin and CORM-2 and CORM-2 resulted in TMRTG values significantly different from the values other three conditions with the important finding that the addition of carboplatin to CORM-2 decreased TMRTG values compared to samples with CORM-2 exposure. Aside from this singular difference in TMRTG values, there was no significant differences in MRTG and TTG values between venom exposed to CORM- 2 alone or the combination of carboplatin and CORM-2. As with B. moojeni venom, the interaction between carboplatin and CORM-2 was significant for TMRTG values, with carboplatin opposing CORM-2 mediated inhibition of the procoagulant activity of $C$. rhodostoma venom. 
In conclusion, carboplatin did not demonstrate any detectable effect on the procoagulant activity of these two venoms, but this compound did in some way partially block the inhibitory effect of CORM-2 on increasing TMRTG values, thus delaying the initiation of clot formation.

\section{Discussion}

The present investigation succeeded in capturing unique observations regarding the effects of four platinoid compounds with different valences on diverse procoagulant venom activities. As mentioned in the Introduction, it was entirely possible that any or all of the four compounds tested (CORM-2, CORM-3, $\mathrm{RuCl}_{3}$, carboplatin) might be expected to interact with similar molecular targets (e.g., histidine, methionine, disulfide bridges) within the enzymes of the venoms tested [8,12-20]. To be sure, the venoms contained metalloproteinases, serine proteases, kallikrein-like enzymes, Factor X-like enzymes, and/or Factor V-like activities [27-35], and the vipers and one lizard chosen evolved in geographically diverse areas of the world. This selection of compounds and venoms permitted remarkably different results to be documented that provide molecular insight into the complex interactions modifying procoagulant activity. For clarity, the various patterns of interaction of the platinoids utilized with venoms will be considered in the order of experimentation as subsequently presented.

With regard to the interaction of CORM-2 and $\mathrm{RuCl}_{3}$, B. moojeni inhibition was possibly secondary to different molecular sites on the procoagulant enzyme(s) inhibited. Specifically, a relatively silent inhibitory interaction by $\mathrm{RuCl}_{3}$ only became important when CORM-2 was introduced. As for C. rhodostoma venom, it appeared that both Ru-based compounds individually inhibited procoagulant activity to an equivalent extent, and when combined, significantly inhibited activity more than when only one inhibitor was present. In the case of E. leucogaster venom procoagulant activity, CORM-2 was a more significant inhibitor than $\mathrm{RuCl}_{3}$, but when combined, inhibition was somewhat greater than when the venom was exposed to CORM-2 alone. Lastly, O. microlepidotus venom procoagulant activity was only inhibited by CORM-2, with the presence of $\mathrm{RuCl}_{3}$ not making any difference in activity without or with CORM-2 presence. Considered as a whole, the results point to potential diversity in binding sites by CORM-2 and $\mathrm{RuCl}_{3}$, associated with an equally unpredictable inhibitory effect.

The experiments involving venom exposures to CORM-3 and $\mathrm{RuCl}_{3}$ also revealed diverse patterns of procoagulant activity inhibition. In the case of $B$. moojeni venom, insignificant inhibition by both CORM-3 and $\mathrm{RuCl}_{3}$ were noted (Figure 4 ), but the inhibitory effects were far more diminutive than that observed with CORM-2 (Figure 1). The reason that the procoagulant activity of venom after $\mathrm{RuCl}_{3}$ exposure was significantly different from venom not exposed to this compound in Figure 4 but not in Figure 1 is a statistical phenomenon - the mean values and variance of the other conditions in Figure 1 overshadowed the condition of $\mathrm{RuCl}_{3}$-exposed venom, but not so in Figure 4. Nevertheless, the effects of $\mathrm{RuCl}_{3}$ on this venom were quantitatively very small. As for C. rhodostoma venom exposed to CORM-3 and $\mathrm{RuCl}_{3}, \mathrm{CORM}-3$ had no discernable effect on procoagulant activity, and when combined with $\mathrm{RuCl}_{3}$, it appeared that CORM-3 partially antagonized $\mathrm{RuCl} 3$-mediated inhibition of procoagulant activity based on an increase in MRTG values compared to venom samples exposed to $\mathrm{RuCl}_{3}$ alone (Figure 4). With regard to P. textilis venom procoagulant activity, $\mathrm{CORM}-3$ and $\mathrm{RuCl}_{3}$ had equivalent inhibitory effects, with the combination of the two Ru-based compounds significantly interacting and significantly increasing inhibition of activity. Finally, as for H. suspectum venom procoagulant activity, only the combination of CORM-3 and $\mathrm{RuCl}_{3}$ exerted meaningful inhibition of activity. In summary, unlike CORM-2, CORM-3 was unpredictably far less potent as a direct inhibitor of procoagulant activity in some cases, and unpredictably enhanced or partially inhibited $\mathrm{RuCl}_{3}$-mediated inhibition of procoagulant activity.

Experimentation involving carboplatin and CORM-2 was in some ways the most fascinating. Simply put, carboplatin by itself had no detectable effects on the procoagulant 
activity of B. moojeni and C. rhodostoma venom; however, carboplatin exposure significantly antagonized CORM-2 mediated inhibition of venom procoagulant activity as evidenced by decreased TMRTG values (Figure 6). While at face value it seems simple enough to imagine a competition between carboplatin and CORM-2 on a common molecular site of similar enzymes, it is far more difficult to explain with such a paradigm why MRTG values did not change as well. As a rule, increases or decreases in thrombin generation are accompanied by concordant decreases or increases in TMRTG values and increases or decreases in MRTG values, respectively. Taken as a whole, while it is clear that a Pt-based compound appears to partially antagonize a Ru-based compound mediated inhibition of procoagulant activity, the precise molecular explanation for the coagulation kinetic changes observed remains to be elucidated.

It is important to note that even if combinations of CORM-2, CORM-3 and $\mathrm{RuCl}_{3}$ are demonstrated in vitro to be more effective than either separately in inhibiting venom enzymatic activity, that is a far cry from being able to be assured that this formulation is not toxic in vivo. To be sure, systemic/local CORM-2 or CORM-3 administrations that would result in circulating or regional concentrations as great or greater than that reported here in vivo has been demonstrated to be benign in animal models too numerous to fully cite, including rabbits [38,39] and rats [40,41]. It is also important to note that the concentrations of CORM-2, CORM-3 and $\mathrm{RuCl}_{3}$ are small, and are dissolved in PBS at $\mathrm{pH}$ 7.4-a not particularly toxic solution. With regard to the nature of each $\mathrm{Ru}$ compound, it is likely that $\mathrm{RuCl}_{3}$ is forming some sort of phosphate ion following the loss of a $\mathrm{Cl}^{-}$in solution that may not be a high energy species, given the physiological milieu. $\mathrm{RuCl}_{3}$ is only hemostatically active in human plasma if dissolved in PBS and not active if suspended in water-but only at 100 times the concentration in plasma as used here in experimentation [37]. In contrast, CORM-2 (and probably CORM-3) likely form a transient, high energy radical during carbon monoxide release for a couple of reasons. First, CORM-2 synthesis involves exposing $\mathrm{RuCl}_{3}$ to high, nonphysiological temperatures in the presence of various solvents containing carbon monoxide-donating compounds or in the presence of carbon monoxide gas at several atmospheres of pressure for hours (patents.google.com/patent/CN107033191A/en; accessed on 10 March 2021). Second, CORM-2 that is inactivated (presumably by complete release of carbon monoxide) does not have the same carbon monoxide-independent inhibitory effects on various enzymes and ion channels as does the form of the compound actively releasing carbon monoxide [7-11]. Taken as a whole, more investigation is needed to determine the suitability of a formulation of such Ru based compounds, which contain molecules that modulate enzymatic function based not just on valance but also on ionic/radical states.

The use of venom rather than isolated enzymes is a limitation of the present study, but the utilization of thrombelastography to assess venom-mediated procoagulant activity in human plasma is very nearly an exercise in individual enzyme interrogation. The initiation of coagulation is a complex threshold event that rapidly consumes available substrate (e.g., fibrinogen). In the case of enzymes that activate prothrombin directly or other proximate serine proteases of the coagulation system, one particular enzyme will be in sufficient abundance with superior rate of catalysis to outcompete other venom enzymes that are present to initiate coagulation-making this one enzyme the de facto "procoagulant activity" responsible for the coagulation kinetics recorded via thrombelastography. In the case of enzymes that are "thrombin-like", as in the example of the serine protease ancrod found in the venom of C. rhodostoma [28], the enzyme will catalyze fibrinogen and factor XIII far more quickly than the contact protein system engaged by the plastic cup and pin, so that the substrates will be consumed by the venom enzyme before the endogenous plasma serine proteases are generated. Or in the case of $H$. suspectum venom, the hemostatically active enzyme is a kallikrein-like enzyme that rapidly initiates contact protein activation of coagulation before factor XII is able to do so as recently reviewed [36]. Given the aforementioned, subsequent inhibition of venom mediated procoagulant activity by the various $\mathrm{Ru}$-based compounds can reasonably be assumed to be primarily due to inactivation of 
the very same enzymes and likely any other similar enzymes present that had previously been outcompeted by the predominant species. In conclusion, despite being composed of several enzymes that might engage the process of coagulation, thrombelastography permits assessment of the kinetically most important enzyme responsible for whole venom procoagulant activity, making the technique an exercise in molecular analysis.

Another important matter to consider when interpreting the data is found in the background literature generated by this laboratory that guided the selection of venom concentrations and inhibitor concentrations $[1-6,36]$. The thrombelastographic paradigm used to characterize venom activity as procoagulant or anticoagulant is performance-based, meaning that venom is added to plasma at a concentration that results in coagulation kinetics that are markedly and statistically significantly different from results observed in normal plasma [1-6,36]. For example, for a venom concentration to be selected for experimentation, it would have to be sufficient to at least half the time to onset of coagulation (e.g., TMRTG) and/or double the maximum velocity of clot growth (e.g., MRTG) [1-3]. This would assure that endogenous processes that would initiate thrombin generation and clot formation via contact protein system engagement are outcompeted kinetically, allowing assessment of the venom enzymes studied. This is the justification for the concentrations of venoms used in the present study. It is also of interest that the concentrations of CORM-2, CORM-3 and $\mathrm{RuCl}_{3}$ were chosen based on the observations obtained in the aforementioned articles $[1-6,36]$ wherein the goal was to determine what concentration would result in a statistically significant reduction in either venom anticoagulant or procoagulant activity. After assessing sixty different venoms over the past five years, it appears that standardized concentrations of CORM-2 (100 $\mu \mathrm{M}$ for most venoms, $1 \mathrm{mM}$ for resistant venoms) have allowed investigation of the efficacy of inhibition by this class of molecule. Using this standard, the present investigation is the first to compare, on a mole-to-mole basis, the efficacy and interactions of different Ru-based molecules and one Pt-based molecule on potential inhibition of the diverse venoms investigated. The variations in concentration and combination of platinoid compound used was designed not to obtain an idealized determination of optimal inhibitory concentrations, but instead to determine in an exploratory spirit if there was variation in inhibitory response as a basis to postulate that multiple molecular sites of interaction existed within the procoagulant enzymes involved. The data would indicate that this goal was achieved, and that his data should serve as a preliminary, hypothesis-generating exercise into these remarkably complex venom-mediated effects on coagulation.

In conclusion, the present study demonstrated that hereto unappreciated binding sites on procoagulant enzymes within diverse venoms with complex proteomes may be vulnerable to inhibition of activity by a variety of Ru-based compounds with different valences, separately or as a formulation. Further, a Pt-based compound was found to antagonize Ru-based compound mediated inhibition of the procoagulant activity of diverse venoms. These observations provide molecular insight into the potentially multiple sites present on such procoagulant enzymes that may be therapeutic targets when designing small molecular weight antivenom molecules. Future investigation is justified to determine the differential response of hemostatically active venoms (e.g., procoagulant, anticoagulant, neurotoxic) to Ru-based compounds of multiple valences and molecular size, in isolation and in formulations of two or more compounds.

\section{Materials and Methods}

\subsection{Chemicals and Human Plasma}

Calcium-free phosphate buffered saline (PBS), CORM-2, CORM-3, ruthenium chloride and carboplatin were obtained from Millipore Sigma (Saint Louis, MO, USA). Venoms dissolved in PBS $(50 \mathrm{mg} / \mathrm{mL})$ were obtained from archived, never thawed aliquots maintained at $-80^{\circ} \mathrm{C}$ in the laboratory that were used in previous investigations $[1-4,11,36]$. Bothrops moojeni and Calloselasma rhodostoma venoms were obtained originally from the National Natural Toxins Research Center at Texas A\&M University (Kingsville, TX, USA). Addi- 
tionally, Echis leucogaster, Heloderma suspectum, Oxyuranus microlepidotus and Pseudonaja textilis venoms were originally purchased from Mtoxins (Oshkosh, WI, USA). Calcium chloride $(200 \mathrm{mM})$ was obtained from Haemonetics Inc., Braintree, MA, USA. Pooled normal human plasma (George King Bio-Medical, Overland Park, KS, USA) that was sodium citrate anticoagulated and maintained at $-80^{\circ} \mathrm{C}$ was used.

\subsection{Thrombelastographic Analyses}

The volumes of subsequently described plasmatic and other additives summed to a final volume of $360 \mu \mathrm{L}$. Samples were composed of $320 \mu \mathrm{L}$ of plasma; $16.4 \mu \mathrm{L}$ of PBS, $20 \mu \mathrm{L}$ of $200 \mathrm{mM} \mathrm{CaCl}_{2}$, and $3.6 \mu \mathrm{L}$ of PBS or venom mixture, which were pipetted into a disposable cup in a thrombelastograph ${ }^{\circledR}$ hemostasis system (Model 5000, Haemonetics Inc., Braintree, MA, USA) at $37^{\circ} \mathrm{C}$, and then rapidly mixed by moving the cup up against and then away from the plastic pin five times. The following viscoelastic parameters described previously $[6,7,10,12,13]$ were measured: time to maximum rate of thrombus generation (TMRTG): this is the time interval (minutes) observed prior to maximum speed of clot growth; maximum rate of thrombus generation (MRTG): this is the maximum velocity of clot growth observed (dynes $/ \mathrm{cm}^{2} /$ second); and total thrombus generation (TTG, dynes $/ \mathrm{cm}^{2}$ ), the final viscoelastic resistance observed after clot formation. Data were collected until a stable maximum amplitude was observed with minimal change for $3 \mathrm{~min}$ as determined by the software.

\subsection{Exposures of Venoms to CORM-2, CORM-3, $\mathrm{RuCl}_{3}$ and Carboplatin}

A selection of venoms was exposed to CORM-2 concentrations (or fractions thereof) demonstrated to inhibit procoagulant activity and placed into plasma at the final venom concentrations previously used in this plasma based, thrombelastographic system [1-4]. Indicated venoms were also exposed to $\mathrm{CORM}-3, \mathrm{RuCl}_{3}$ and carboplatin in various combinations subsequently presented. The specific exposures for each venom are as follows.

B. moojeni. This venom was exposed to 0 or $1 \mathrm{mM} \mathrm{CORM}-2$ or CORM-3 in the presence of 0 or $100 \mu \mathrm{M} \mathrm{RuCl}_{3}$ in PBS for at least $5 \mathrm{~min}$ at room temperature prior to no additives, exposed to $1 \mathrm{mM}$ CORM-2 or CORM-3, exposed to $100 \mu \mathrm{M} \mathrm{RuCl} 3$ in PBS, or exposed to $1 \mathrm{mM}$ CORM-2 or CORM-3 and $100 \mu \mathrm{M} \mathrm{RuCl}_{3}$ in PBS for at least $5 \mathrm{~min}$ at room temperature prior to placement into plasma followed immediately with commencement of thrombelastographic analysis. This venom was also exposed to no additives, $1 \mathrm{mM}$ CORM-2, $100 \mu \mathrm{M}$ carboplatin, or exposed to $1 \mathrm{mM}$ CORM-2 and $100 \mu \mathrm{M}$ carboplatin in another series of experiments. The final concentration of this venom in plasma was $2 \mu \mathrm{g} / \mathrm{mL}$.

C. rhodostoma. This venom was exposed to no additives, exposed to $50 \mu \mathrm{M}$ CORM-2 or CORM-3, exposed to $50 \mu \mathrm{M} \mathrm{RuCl}{ }_{3}$ in PBS, or exposed to $50 \mu \mathrm{M}$ CORM-2 or CORM-3 and $50 \mu \mathrm{M} \mathrm{RuCl}_{3}$ in PBS for at least $5 \mathrm{~min}$ at room temperature prior to placement into plasma followed immediately with commencement of thrombelastographic analysis. 0 or $50 \mu \mathrm{M}$ CORM-2 or CORM-3 in the presence of 0 or $50 \mu \mathrm{M} \mathrm{RuCl} 3$ in PBS for at least $5 \mathrm{~min}$ at room temperature prior to placement into plasma followed immediately with commencement of thrombelastographic analysis. This venom was also exposed to no additives, $100 \mu \mathrm{M}$ CORM-2, $100 \mu \mathrm{M}$ carboplatin, or $100 \mu \mathrm{M}$ CORM-2 and $100 \mu \mathrm{M}$ carboplatin in another series of experiments. The final concentration of this venom in plasma was $5 \mu \mathrm{g} / \mathrm{mL}$.

E. leucogaster. This venom was exposed no additives, $100 \mu \mathrm{M}$ CORM-2, $100 \mu \mathrm{M} \mathrm{RuCl}_{3}$, or $100 \mu \mathrm{M}$ CORM-2 and $100 \mu \mathrm{M} \mathrm{RuCl}_{3}$ in PBS for at least $5 \mathrm{~min}$ at room temperature prior to placement into plasma, followed immediately with commencement of thrombelastographic analysis. The final concentration of this venom in plasma was $1 \mu \mathrm{g} / \mathrm{mL}$.

O. microlepidotus. This venom was exposed to no additives, $100 \mu \mathrm{M}$ CORM-2, $100 \mu \mathrm{M}$ $\mathrm{RuCl}_{3}$, or $100 \mu \mathrm{M} \mathrm{CORM}-2$ and $100 \mu \mathrm{M} \mathrm{RuCl}_{3}$ in PBS for at least $5 \mathrm{~min}$ at room temperature prior to placement into plasma, followed immediately with commencement of thrombelastographic analysis. The final concentration of this venom in plasma was $1 \mu \mathrm{g} / \mathrm{mL}$. 
P. textilis. This venom was exposed to to no additives, $100 \mu \mathrm{M} \mathrm{CORM-3,} 100 \mu \mathrm{M} \mathrm{RuCl}_{3}$, or $100 \mu \mathrm{M} \mathrm{CORM}-3$ and $100 \mu \mathrm{M} \mathrm{RuCl}_{3}$ in PBS for at least $5 \mathrm{~min}$ at room temperature prior to placement into plasma, followed immediately with commencement of thrombelastographic analysis. The final concentration of this venom in plasma was $0.1 \mu \mathrm{g} / \mathrm{mL}$.

H. suspectum. This venom was exposed to no additives, $1 \mathrm{mM} \mathrm{CORM-3,} 100 \mu \mathrm{M} \mathrm{RuCl}_{3}$, or $1 \mathrm{mM} \mathrm{CORM}-3$ and $100 \mu \mathrm{M} \mathrm{RuCl}_{3}$ in PBS for at least $5 \mathrm{~min}$ at room temperature prior to placement into plasma, followed immediately with commencement of thrombelastographic analysis. The final concentration of this venom in plasma was $10 \mu \mathrm{g} / \mathrm{mL}$.

Given the aforementioned, the experimental conditions utilized were: (1) V conditionvenom in PBS; (2) Ru(II) condition-venom exposed to CORM-2 or CORM-3; (3) Ru(III) condition - venom exposed to $\mathrm{RuCl}_{3}$; (4) $\mathrm{Ru}(\mathrm{II}+\mathrm{III})$ condition — venom exposed to CORM-2 or CORM-3 and $\mathrm{RuCl}_{3}$ simultaneously; (5) $\mathrm{Pt}(\mathrm{II})$ condition-venom exposed to carboplatin; and (6) $\mathrm{Pt}+\mathrm{Ru}$ condition - venom exposed to carboplatin and CORM-2. After the $5 \mathrm{~min}$ period at room temperature, $3.6 \mu \mathrm{L}$ of one of these solutions was added to the plasma sample in the plastic thrombelastograph cup.

\subsection{Statistical Analyses and Graphics}

Data are presented as mean \pm SD. Graphics were generated with a commercially available program (Origin2020b, OriginLab Corporation, Northampton, MA, USA). Experimental conditions were composed of $\mathrm{n}=6$ replicates per condition as this provides a statistical power $>0.8$ with $p<0.05$ utilizing these techniques [1-4]. A statistical program was used for one-way analyses of variance (ANOVA) comparisons between conditions, followed by Holm-Sidak post hoc analysis. Additional analysis with two-way ANOVA was performed to detect significant interactions between CORM- 2 and $\mathrm{RuCl}_{3}, \mathrm{CORM}-3$ and $\mathrm{RuCl}_{3}$, and CORM-2 and carboplatin regarding changes in venom procoagulant activity. All analyses were performed with commercial software (SigmaPlot 14, Systat Software, Inc., San Jose, CA, USA). $p<0.05$ was considered significant.

Funding: This project received no external funding.

\section{Institutional Review Board Statement: None.}

Informed Consent Statement: None.

Data Availability Statement: All data generated are presented in this manuscript.

Conflicts of Interest: The author does not have any conflict of interest.

\section{References}

1. Nielsen, V.G.; Bazzell, C.M. Carbon monoxide releasing molecule-2 inhibition of snake venom thrombin-like activity: Novel biochemical "brake"? J. Thromb. Thrombolysis 2017, 43, 203-208. [CrossRef]

2. Nielsen, V.G.; Frank, N.; Matika, R.W. Carbon monoxide inhibits hemotoxic activity of Elapidae venoms: Potential role of heme. BioMetals 2018, 31, 51-59. [CrossRef]

3. Nielsen, V.G.; Frank, N. Role of heme modulation in inhibition of Atheris, Atractaspis, Causus, Cerastes, Echis, and Macrovipera hemotoxic venom activity. Hum. Exp. Toxicol. 2019, 38, 216-226. [CrossRef]

4. Nielsen, V.G.; Frank, N.; Afshar, S. De Novo Assessment and Review of Pan-American Pit Viper Anticoagulant and Procoagulant Venom Activities via Kinetomic Analyses. Toxins 2019, 11, 94. [CrossRef]

5. Suntravat, M.; Langlais, P.R.; Sánchez, E.E.; Nielsen, V.G. CatroxMP-II: A heme-modulated fibrinogenolytic metalloproteinase isolated from Crotalus atrox venom. BioMetals 2018, 31, 585-593. [CrossRef]

6. Nielsen, V.G. Carbon monoxide inhibits the anticoagulant activity of phospholipase A2 purified from Crotalus adamanteus venom. J. Thromb. Thrombolysis 2019, 47, 73-79. [CrossRef] [PubMed]

7. Gessner, G.; Sahoo, N.; Swain, S.M.; Hirth, G.; Schönherr, R.; Mede, R.; Westerhausen, M.; Brewitz, H.H.; Heimer, P.; Imhof, D.; et al. CO-independent modification of $\mathrm{K}+$ channels by tricarbonyldichlororuthenium(II) dimer (CORM-2). Eur. J. Pharmacol. 2017, 815, 33-41. [CrossRef]

8. Southam, H.M.; Smith, T.W.; Lyon, R.L.; Liao, C.; Trevitt, C.R.; Middlemiss, L.A.; Cox, F.L.; Chapman, J.A.; El-Khamisy, S.F.; Hippler, M.; et al. A thiol-reactive $\mathrm{Ru}(\mathrm{II})$ ion, not $\mathrm{CO}$ release, underlies the potent antimicrobial and cytotoxic properties of CO-releasing molecule-3. Redox Biol. 2018, 18, 114-123. [CrossRef]

9. Nielsen, V.G. The anticoagulant effect of Apis mellifera phospholipase A2 is inhibited by CORM-2 via a carbon monoxideindependent mechanism. J. Thromb Thrombolysis 2020, 49, 100-107. [CrossRef] 
10. Nielsen, V.G.; Wagner, M.T.; Frank, N. Mechanisms Responsible for the Anticoagulant Properties of Neurotoxic Dendroaspis Venoms: A Viscoelastic Analysis. Int. J. Mol. Sci. 2020, 21, 2082. [CrossRef] [PubMed]

11. Nielsen, V.G. Ruthenium, Not Carbon Monoxide, Inhibits the Procoagulant Activity of Atheris, Echis, and Pseudonaja Venoms. Int. J. Mol. Sci 2020, 21, 2970. [CrossRef]

12. Lazić, D.; Arsenijević, A.; Puchta, R.; Bugarčić, Ž.D.; Rilak, A. DNA binding properties, histidine interaction and cytotoxicity studies of water soluble ruthenium(II) terpyridine complexes. Dalton Trans. 2016, 45, 4633. [CrossRef]

13. Hanif, M.; Meier, S.M.; Adhireksan, Z.; Henke, H.; Martic, S.; Movassaghi, S.; Labib, M.; Kandioller, W.; Jamieson, S.M.F.; Hejl, M.; et al. Functionalization of Ruthenium(II)(n6-p-cymene)(3-hydroxy-2-pyridone) Complexes with (Thio) Morpholine: Synthesis and Bioanalytical Studies. ChemPlusChem 2017, 82, 841-847. [CrossRef]

14. Stanic-Vucinic, D.; Nikolic, S.; Vlajic, K.; Radomirovic, M.; Mihailovic, J.; Velickovic, T.C.; Grguric-Sipka, S. The interactions of the ruthenium(II)-cymene complexes with lysozyme and cytochrome c. J. Biol. Inorg. Chem. 2020, 25, 253-265. [CrossRef]

15. Yocom, K.M.; Shelton, J.B.; Shelton, J.R.; Schroeder, W.A.; Worosila, G.; Isied, S.S.; Bordignon, E.; Gray, H.B. Preparation and characterization of a pentaammineruthenium(III) derivative of horse heart ferricytochrome c. Proc. Natl. Acad. Sci. USA 1982, 79, 7052-7055. [CrossRef] [PubMed]

16. Kratz, K.; Keppler, B.K.; Messori, L.; Smith, C.; Baker, E.N. Protein-binding Properties of two Antitumour Ru(III) Complexes to Human Apotransferrin and Apolactoferrin. Met. Based Drugs 1994, 1, 169-173. [CrossRef]

17. Webb, M.I.; Walsby, C.J. Albumin binding and ligand-exchange processes of the Ru(III) anticancer agent NAMI-A and its bis-DMSO analogue determined by ENDOR spectroscopy. Dalton Trans. 2015, 44, 17482. [CrossRef] [PubMed]

18. Ren, C.; Bobst, C.E.; Kaltashov, I.A. Exploiting His-Tags for Absolute Quantitation of Exogenous Recombinant Proteins in Biological Matrices: Ruthenium as a Protein Tracer. Anal. Chem. 2019, 91, 7189-7198. [CrossRef]

19. Das, D.; Dutta, S.; Dowerah, D.; Deka, R.C. Unveiling the Role of Hydrogen Bonding and g-Tensor in the Interaction of Ru-BisDMSO with Amino Acid Residue and Human Serum Albumin. J. Phys. Chem. B 2020, 124, 6459-6474. [CrossRef] [PubMed]

20. Artiaga, G.; Iglesias-Jiménez, A.; Moreno-Gordaliza, E.; Mena, M.L.; Gómez-Gómez, M.M. Differences in binding kinetics, bond strength and adduct formation between Pt-based drugs and S- or N-donor groups: A comparative study using mass spectrometry techniques Eur. J. Pharm. Sci. 2019, 132, 96-105. [CrossRef]

21. Watanabe, L.; Shannon, J.D.; Valente, R.H.; Rucavado, A.; Alape-Girón, A.; Kamiguti, A.S.; Theakston, R.D.G.; Fox, J.W.; Gutiérrez, J.M.; Arni, R.K. Amino acid sequence and crystal structure of BaP1, a metalloproteinase from Bothrops asper snake venom that exerts multiple tissue-damaging activities. Protein Sci. 2003, 12, 2273-2281. [CrossRef] [PubMed]

22. Markland, F.S., Jr.; Swenson, S. Snake venom metalloproteinases. Toxicon 2013, 62, 3-18. [CrossRef] [PubMed]

23. Calvete, J.J.; Schrader, M.; Raida, M.; McLane, M.A.; Romero, A.; Niewiarowski, S. The disulphide bond pattern of bitistatin, a disintegrin isolated from the venom of the viper Bitis arietans. FEBS Lett. 1997, 416, 197-202. [CrossRef]

24. Braud, S.; Parry, M.A.; Maroun, R.; Bon, C.; Wisner, A. The contribution of residues 192 and 193 to the specificity of snake venom serine proteinases. J. Biol. Chem. 2000, 275, 1823-1828. [CrossRef] [PubMed]

25. Valentin, E.; Lambeau, G. What can venom phospholipases A(2) tell us about the functional diversity of mammalian secreted phospholipases A(2)? Biochimie 2000, 82, 815-831. [CrossRef]

26. Soares, A.M.; Giglio, J.R. Chemical modifications of phospholipases A2 from snake venoms: Effects on catalytic and pharmacological properties. Toxicon 2003, 42, 855-868. [CrossRef]

27. Aguiar, W.D.S.; Galizio, N.D.C.; Serino-Silva, C.; Sant'Anna, S.S.; Grego, K.F.; Tashima, A.K.; Nishiduka, E.S.; Morais-Zani, K.; Tanaka-Azevedo, A.M. Comparative compositional and functional analyses of Bothrops moojeni specimens reveal several individual variations. PLoS ONE 2019, 14, e0222206. [CrossRef] [PubMed]

28. Tang, E.L.; Tan, C.H.; Fung, S.Y.; Tan, N.H. Venomics of Calloselasma rhodostoma, the Malayan pit viper: A complex toxin arsenal unraveled. J. Proteom. 2016, 148, 44-56. [CrossRef]

29. Patra, A.; Kalita, B.; Chanda, A.; Mukherjee, A.K. Proteomics and antivenomics of Echis carinatus carinatus venom: Correlation with pharmacological properties and pathophysiology of envenomation. Sci. Rep. 2017, 7, 17119. [CrossRef]

30. Yamada, D.; Morita, T. CA-1 method, a novel assay for quantification of normal prothrombin using a Ca ${ }^{2+}$-dependent prothrombin activator, carinactivase-1. Thromb. Res. 1999, 94, 221-226. [CrossRef]

31. Chen, Y.L.; Tsai, I.H. Functional and sequence characterization of coagulation factor IX/factor X-binding protein from the venom of Echis carinatus leucogaster. Biochemistry 1996, 35, 5264-52671. [CrossRef]

32. Koludarov, I.; Jackson, T.N.; Sunagar, K.; Nouwens, A.; Hendrikx, I.; Fry, B.G. Fossilized venom: The unusually conserved venom profiles of Heloderma species (beaded lizards and gila monsters). Toxins 2014, 6, 3582-3595. [CrossRef]

33. Sanggaard, K.W.; Dyrlund, T.F.; Thomsen, L.R.; Nielsen, T.A.; Brøndum, L.; Wang, T.; Thøgersen, I.B.; Enghild, J.J. Characterization of the gila monster (Heloderma suspectum suspectum) venom proteome. J. Proteom. 2015, 117, 1-11. [CrossRef]

34. Herrera, M.; Fernández, J.; Vargas, M.; Villalta, M.; Segura, Á.; León, G.; Angulo, Y.; Paiva, O.; Matainaho, T.; Jensen, S.D.; et al. Comparative proteomic analysis of the venom of the taipan snake, Oxyuranus scutellatus, from Papua New Guinea and Australia: Role of neurotoxic and procoagulant effects in venom toxicity. J. Proteom. 2012, 75, 2128-2140. [CrossRef]

35. McCleary, R.J.; Sridharan, S.; Dunstan, N.L.; Mirtschin, P.J.; Kini, R.M. Proteomic comparisons of venoms of long-term captive and recently wild-caught Eastern brown snakes (Pseudonaja textilis) indicate venom does not change due to captivity. J. Proteom. 2016, 144, 51-62. [CrossRef] 
36. Nielsen, V.G.; Frank, N. The kallikrein-like activity of Heloderma venom is inhibited by carbon monoxide. J. Thromb. Thrombolysis 2019, 47, 533-539. [CrossRef] [PubMed]

37. Nielsen, V.G. Platinoid effects on human plasmatic coagulation kinetics: A viscoelastic analysis. J. Thromb. Thrombolysis 2021. [CrossRef] [PubMed]

38. Nielsen, V.G.; Chawla, N.; Mangla, D.; Gomes, S.B.; Arkebauer, M.R.; Wasko, K.A.; Sadacharam, K.; Vosseller, K. Carbon monoxidereleasing molecule-2 enhances coagulation in rabbit plasma and decreases bleeding time in clopidogrel/aspirin-treated rabbits. Blood Coagul. Fibrinolysis 2011, 22, 756-759. [CrossRef] [PubMed]

39. Stagni, E.; Privitera, M.G.; Bucolo, C.; Leggio, G.M.; Motterlini, R.; Drago, F. A water-soluble carbon monoxide-releasing molecule (CORM-3) lowers intraocular pressure in rabbits. Br. J. Ophthalmol. 2009, 93, 254-257. [CrossRef] [PubMed]

40. Zhang, S.; Xu, Y.; Zhu, J.; Ma, J.; Niu, Q.; Wang, X. Carbon monoxide attenuates LPS-induced myocardial dysfunction in rats by regulating the mitochondrial dynamic equilibrium. Eur. J. Pharm. 2020, 889, 173726. [CrossRef] [PubMed]

41. Bai, J.; Bai, Y.; Wang, X.P.; Zheng, W.C.; Zhang, L.M. Carbon Monoxide-Releasing Molecule-3 Ameliorates Acute Lung Injury in a Model of Hemorrhagic Shock and Resuscitation: Roles of p38MAPK Signaling Pathway. Shock 2020. [CrossRef] [PubMed] 